\title{
EATING IDENTITY: AN EXPLORATION OF FIJIAN FOODWAYS IN THE ARCHAEOLOGICAL PAST
}

\author{
Sharyn Jones \\ Northern Kentucky University \\ joness33@nku.edu
}

\begin{abstract}
I argue that group identity may be used to address fundamental anthropological concepts that are critical for understanding Pacific Island peoples and their cultures from a long-term perspective. Specifically, I explore foodways as a locus of archaeological material culture through the theoretical lens of materiality. I examine archaeological and ethnographic data that illuminate foodways in the Fiji Islands. The archaeological information derives from four islands and a variety of coastal sites across the Fiji archipelago. I illustrate that in both the past and present food, zooarchaeological remains, and associated material culture may be used to understand social changes and identity as expressed in eating behaviors and patterns in archaeological fauna. By using materiality and a broad comparative frame of reference archaeologists may better understand what it means to be Fijian.
\end{abstract}

\section{INTRODUCTION}

In almost all human societies food plays a central role Social interactions surrounding foodways and the items consumed are steeped in symbolism, ritual, and meaning. Some researchers have even argued that food is the key to our humanity (Warangham 2009; Pollan 2013). All creatures must eat to live, but the nuanced expressions of human foodways and their associated meanings crossculturally are highly varied. Even within well-established archaeological cultures, evidence of variation in foodways may be found at a range of levels including: temporally (related to shifts in broad culture phases); geographically; and at village and household levels of analysis. In this paper I argue that by examining food from the theoretical perspective of materiality and embodied repetitive action, we can better understand its social context and gain insights into the complex negotiation of human identity in the past. One aspect of this endeavor relates to ritual and may be investigated though archaeological features and material culture remains related to food. In daily life, meaning is created in a performative context and through repeated actions of food preparation, eating, and associated events. Exploring relationships between cuisine, material culture, and domestic archaeological features informs our explanations of the way rituals reproduce social life including identity. However, articulating this information with actual archaeological features and objects is a challenge. The rich body of archaeology and ethnography in the Pacific Islands offers an opportunity that is ripe for the investigation of these issues. Herein, I begin with an explanation of how I define identity for the purpose of this paper and what I intend to explain with this work.

The concept of identity has played a critical role in the history of archaeological endeavors even before the term was regularly used, analytically examined, theorized, and applied specifically to the study of material culture in the past. Fundamentally, archaeological interpretations involve assumptions about the connections between material culture and human identity (Casella and Fowler 2005; Gilchrist 1999; Insoll 2007; Pierce et al. 2016; Twiss 2007, 2012). At a basic level, group identity, which I am primarily concerned with here, may be defined as the expression and experiences of affiliations, affinities, and voluntary or involuntary community memberships (Pierce et al. 2016; Twiss 2015:189). Ethnicity is another more specific expression of group identity that implies a connection via shared history, culture, and even ancestry. People experience identity and it has many moving parts, including: age, social status, gender, ethnicity, religious affiliations, and many other potential elements. The material components to identity that include archaeologically visible culinary signatures have been studied in some detail (Twiss 2007; White and Beaudry 2009). Nevertheless, describing identity from an archaeological perspective has been challenging and fraught with academic controversy over the years because these social phenomena are in flux, they are situationaldependent, and they involve much more than material culture. For over a decade archaeologists have recognized that expressions of identity are complex (Meskell 2002, 2005). Therefore, explanations based in large part on material phenomena fail to capture such a complicated, temporary, and relational form of expression. People may belong to several different identity groups at any point in time and they negotiate identity through a range of arenas and material media (Casella and Fowler 2005; Insoll 2007; Pierce et al. 2016). However, it is clear that rituals of sociality and consumption performatively make culture and society — food related identity thus feels natural and 


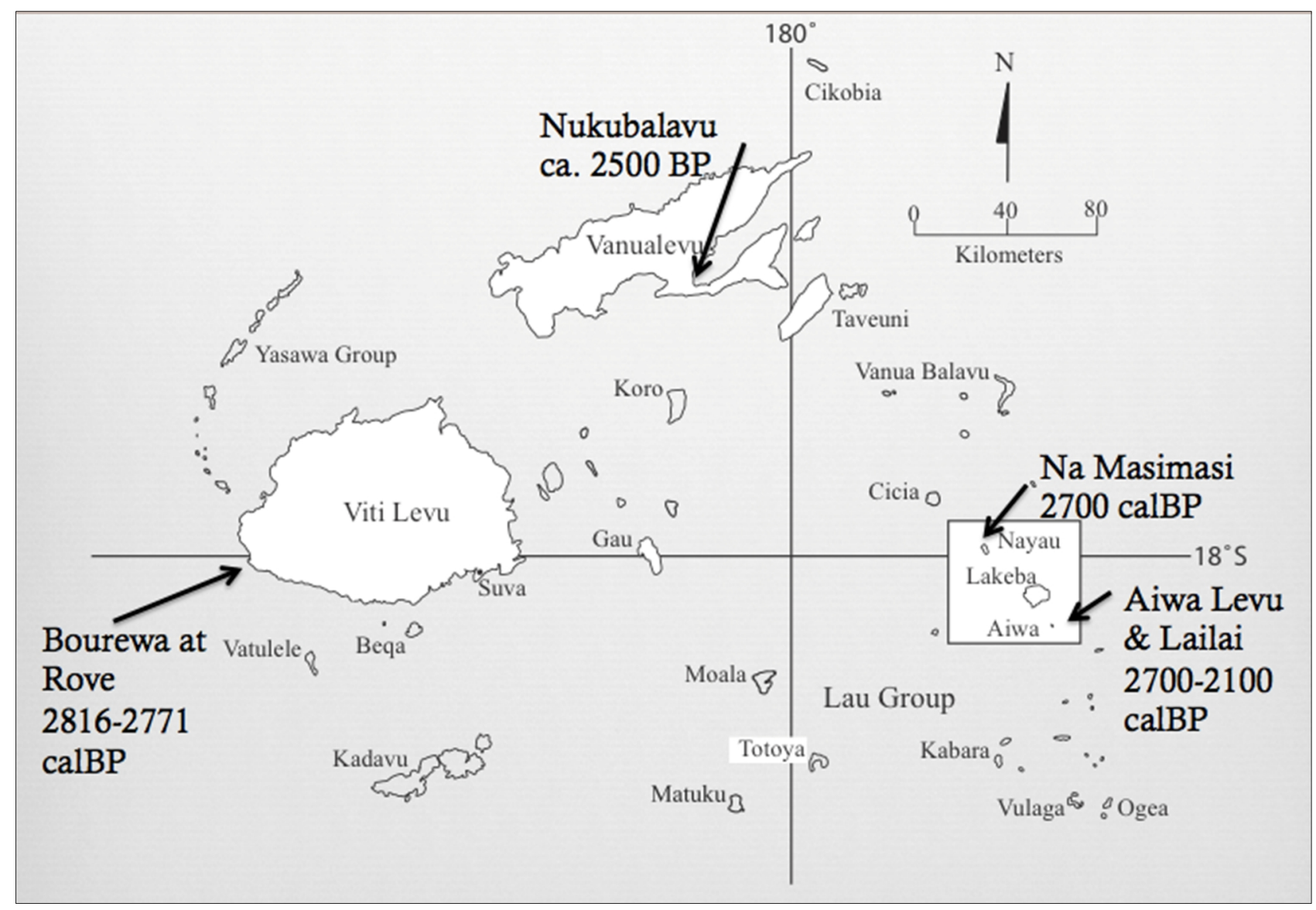

Figure 1. Map of the Fiji Islands. The sites mentioned in the text are indicated by arrows.

real to members of the group (Counihan 2004; Franklin and Fesler 1999; Pierce et al. 2016).

For the purposes of my study, the locus of analysis I focus on is one of an extended duration, a long term perspective, that specifically relates to communities and their preferences for food, as well as the material culture of food (that includes food remains and the vessels people cooked in, served in, and stored food in). I focus on broad levels of analysis, vs. individual identity. I argue that there is a Fijian form of identity expression or perhaps more specifically, a traditional Fijian ethnicity and this formed a social reality that we might come to understand via the material (Chenoweth 2009). Fijian identity may be understood in part from the remains of past foodways and cuisine, which exhibit some variations in material characteristics across space and time (on different islands and/or over temporal periods). I argue that this identity is simultaneously reinforced as it evolves in daily life and in rituals of food. In sum, Fijian identity is inherently fluid as well as deeply rooted in culture, history, and practice.

The related concept of materiality is central to our understanding of the relationship between identity and food. Materiality can be defined as the recursive exchange between people and things (Lazzari 2005:128). When applied to archaeology this approach recognizes that human actions and the qualities of things, or material items including food, are engaged in a complex evolving and fluid relationship (Hodder and Cressford 2004; Hodder and Meskell 2011; Meskell 2002; Wilson 2010). Materiality shifts the focus from a more traditional debate and an oversimplified dichotomy between material objects as either functional or symbolic. Indeed, material culture embodies both. A focus on materiality is a way to interweave objects, ideologies, memory, histories, and practice (Meskell 2005:2). This allows us to understand the meaning of an object based on the performative context (rather than an understanding based simply on physical qualities). As such, the physical nature of an artifact is part of social practice. In this way, material culture is created, recreated, and memorialized through actions and ideologies. This is the framework I am working with to explore and interpret foodways and identity across Fiji's history and archaeological past.

\section{FOODWAYS IN FIJI}

To explore foodways and identity I draw from ethnographic and archaeological data to better understand the meaning and social context of food. As in many cultures, Fijian rituals often involve food and eating. Fijians have a deep history of ritualized foodways and feasting that blurs categorical notions of secular and sacred (O’Day 2004). Rituals may involve quotidian 
activities that do, or do not reference mythical and spiritual concepts. Ethnographic studies clearly suggest that foodways are critical for reproducing social order, marking gender and ethnicity, and creating and maintaining meaning (Becker 1995; Hocart 1929; Jones 2009a; Sahlins 1983; Tomlinson 2014; Toren 1990, 1998, 2009). Nevertheless, archaeologists working in Fiji have typically engaged with identity using ceramic evidence as the basis for defining groups and reconstructing culture histories (Best 1984; Burley 2005, 2013; Clark; 1999, 2009). While there are disputes about the exact dates for Fijian culture historical phases, in general they are relatively well-established and begin with the Lapita occupation marked by the presence of dentate pottery around 3000 BP (Best 1984; Burley 2012, 2013). Subsequent phases are based on variations in vessel form and decoration and include the Plainware phase (ca. 25002100 BP), the Navatu period (ca. 2100-950 BP), and the Vuda or Ra period (ca. 950-present). These common and generally accepted ceramic traditions of Fijian prehistory provide a culture historical architecture for the interpretation of site chronology, material culture, and even social issues. Nevertheless, archaeological interpretations of Fijian prehistory correlate ceramic styles and forms with peoples but rarely examine the more complex topics of group identity and ethnicity. For example, ceramics decorated with dentate designs have been conceptualized as the signature of the Lapita peoples, the first occupants of the islands of Fiji, but we have yet to understand how Lapita cuisine compared to the foodways of the Lapita descendants who made and used other forms of pottery. There has been relatively little discussion of Lapita group identity by archaeologists working in Fiji. Moreover, while ceramics have held a privileged position among archaeological artifacts, many other forms of material culture and foodways specifically have received relatively little attention until recently. Importantly, an understanding of the ways that pottery relates to other forms of material culture, in particular food culture remains to be examined.

Food refuse and non-ceramic food-related artifacts have often been ignored as a locus of social identity and ethnicity in Fiji (and elsewhere in the Pacific islands). Like ceramics, foodways communicate social messages and may be expected to change in tandem with broader cultural shifts over time. My approach to foodways is analogous to Yvonne Marshall's interpretation of Lapita ceramics, "In the face of ongoing migration and colonization, change is an ever-present, inescapable facet of life and what we see in the stability of the lived assemblage is a societal anchor generating a continuity that enables change without social collapse" (Marshall 2008:81). I argue that trends in continuity and subtle changes in foodways over time are where we should expect to find information that illuminates identity, ethnicity, and other social issues in specific Fijian sites.

In the Pacific Islands ritualized quotidian activities include food collection, preparation, and consumption in a variety of contexts. Food is a central locus of ritual and as such both regular meals and feasts may be used as opportunities for exchange, cultural reproduction, tribute, and communion with the ancestors and the gods (Jones 2009a; Toren 1998). Social identity is a key component of ritual as gender, class, power, and social status are all markers that are highlighted and reinforced in daily activities. In particular, food-related activates provide rich fodder for exploring and understanding the multifaceted aspects of identity. The archaeological material correlates for ritual and social identity may be found in the contextual relationships between architecture, features, kitchens, earth ovens, hearths, ceramics, and food remains. All of these are abundant in Fijian archaeological sites as well as contemporary villages, which may serve as ethnographic analogs.

\section{METHODS}

In the three study areas/sites where I excavated (Vanua Levu, Nayau, Aiwa Levu, and Aiwa Lailai) the excavations followed standard procedures reported elsewhere (Jones et al. 2007). Material from the excavated units was screened through nested sieves of $12.7 \mathrm{~mm}, 6.4$ $\mathrm{mm}$, and $3.2 \mathrm{~mm}$ mesh. At Nukubalavu, on Vanua Levu all sediment was water screened. Collected sediment was also run through $1.6 \mathrm{~mm}$ mesh at regular intervals to determine if small items were falling through the screens. However, the material culture in the matrix was easily captured in the $6.4-3.2 \mathrm{~mm}$ mesh. Excavations were conducted in arbitrary $10 \mathrm{~cm}$ levels, following natural stratigraphy whenever possible. Cultural materials were collected from the screens, including bone, shell, pottery, lithics, non-local rocks, fire cracked rocks, and any additional manuports and artifacts. Standardized field forms were used to record the excavations. The site of Bourewa was excavated by Patrick Nunn who has described his work in detail in many publications; the initial report was published in 2004 (Nunn et al. 2004). Larger mesh screens were used at Bourewa and as a result the recovered faunal material includes primarily large specimens.

The faunal remains were examined following standard zooarcheological procedures. My comparative collection is housed at the archaeological laboratory at Northern Kentucky University and includes over 2500 specimens (vertebrates and invertebrates), a large proportion of which are tropical Pacific Island fauna collected by the author. The collection includes multiple individuals of common Central Pacific families, genera, and species and a variety of size and age classes. The bones of all taxa were counted, weighed, and modifications recorded. The number of identified specimens per taxon (NISP) is the basic specimen count used; this includes bones and shells that were not identified to a specific taxonomic level. Efforts were made to identify the faunal material to the most specific taxonomic level possible. 
Table 1. Summary of the archaeological data and site characteristics referenced in the text.

\begin{tabular}{|c|c|c|c|c|c|}
\hline Site & Island & Date & $\begin{array}{l}\text { Ceramic } \\
\text { Phases }\end{array}$ & References & Characteristics of Fauna \\
\hline Bourewa & Viti Levu & 2816-2771 BP & $\begin{array}{l}\text { Lapita \& post } \\
\text { Lapita }\end{array}$ & $\begin{array}{l}\text { Nunn et al. 2004; } \\
\text { Nunn \& Petchey } \\
2013\end{array}$ & $\begin{array}{l}>4000 \text { identified vertebrate } \\
\text { NISP. } \\
\text { Marine reef resources (small- } \\
\text { large-bodied including sea } \\
\text { turtle). megapodes, iguana, \& } \\
\text { domesticated animals. }\end{array}$ \\
\hline $\begin{array}{l}\text { Aiwa } 1 \text { \& Dau } \\
\text { Rockshelter }\end{array}$ & $\begin{array}{l}\text { Aiwa Levu \& } \\
\text { Aiwa Lailai, Lau } \\
\text { Group }\end{array}$ & $\begin{array}{l}2700 \text { BP-Vuda/Ra phase } \\
\text { (historical period) }\end{array}$ & $\begin{array}{l}\text { Late Lapita, } \\
\text { Plainware \& Post } \\
\text { Lapita }\end{array}$ & $\begin{array}{l}\text { Jones } 2009 \text { b; } \\
\text { Jones et al. } \\
2007 \text {; O'Day et } \\
\text { al. } 2003\end{array}$ & $\begin{array}{l}>10,000 \text { vertebrate NISP } \\
5000 \text { invertebrates. } \\
\text { Small-bodied reef fishes and } \\
\text { invertebrates. }\end{array}$ \\
\hline Na Masimasi & $\begin{array}{l}\text { Nayau, Lau } \\
\text { Group }\end{array}$ & $\begin{array}{l}2700 \mathrm{cal} \mathrm{BP} \\
1930 \mathrm{cal} . \mathrm{BP}\end{array}$ & $\begin{array}{l}\text { Lapita, } \\
\text { Plainware, \& } \\
\text { Navatu }\end{array}$ & $\begin{array}{l}\text { Jones 2009a, } \\
\text { 2009b; Jones \& } \\
\text { Quinn 2009; } \\
\text { O'Day et al. } \\
2003\end{array}$ & $\begin{array}{l}>12,000 \text { vertebrates } \\
3000 \text { invertebrates. } \\
\text { Early assemblage with very } \\
\text { small-bodied marine fishes. } \\
\text { Later assemblage includes more } \\
\text { diversity and some } \\
\text { domesticated animals. }\end{array}$ \\
\hline Nukubalavu 1 & Vanua Levu & ca. 2800 BP- 600 BP & $\begin{array}{l}\text { Late Lapita, } \\
\text { Plainware \& } \\
\text { Navatu }\end{array}$ & $\begin{array}{l}\text { Jones and } \\
\text { Cramb in prep.; } \\
\text { Jones et al. } 2014\end{array}$ & $\begin{array}{l}<200 \text { identified vertebrates \& } \\
>25,000 \text { shellfish. Abundant and } \\
\text { diverse invertebrate assemblage } \\
\text { with little change over time. }\end{array}$ \\
\hline
\end{tabular}

\section{OVERVIEW OF THE ARCHAEOLOGICAL DATA}

For this investigation I compare and contrast information from five sites on four different islands in Fiji using both zooarchaeological material I have analyzed, and my own ethnographic observations (Figure 1). The data ranges in time from the early Lapita period to the present (Table 1). The sites are located across the Fijian archipelago, including the islands of Viti Levu, Vanua Levu, and three islands in the Lau Group. Each faunal assemblage has several overarching characteristics that distinguish it from the other sites. Yet, there are also broad similarities. The data suggests some fine-grained local variations and subtle shifts in foodways at the four study areas.

First, sites along the Rove Peninsula of Viti Levu, have produced the earliest evidence for occupation in Fiji. Patrick Nunn conducted these excavations. I analyzed the vertebrate fauna, which includes over 4000 identified specimens weighing over $6 \mathrm{~kg}$. I did not examine the invertebrate fauna. Nunn has recently revised his chronology and argues that the Rove Peninsula was occupied by Lapita people between 2816 and 2771 BP (Nunn et al. 2004; Nunn and Petchey 2013).

Second, several rockshelter sites (Dau Rockshelter and Aiwa 1) on the limestone islands of Aiwa Levu and Aiwa Lailai in the Lau Group have produced dentate pottery and a range of dates correlating with the late Lapita and Plainware periods beginning in 2700 BP (Jones 2009b; Jones et al. 2007; O'Day et al. 2003). These islands measure 1.2 and $1 \mathrm{~km}^{2}$. A total of $9 \mathrm{~m}^{2}$ were excavated at Dau Rockshelter and Aiwa 1. The fauna from the Aiwa sites is highly diverse and includes over 10,000 bones and twice as many invertebrates. The sites provide data that supports an interpretation of continual occupation and use of these tiny islands into contemporary times.

Third, the site of $\mathrm{Na}$ Masimasi is also located in the Lau Group on the island of Nayau (Jones 2009a; O'Day et al. 2003). It is positioned on the beach back at the southeast end of the island, and includes a Lapita phase occupation. A total of $8 \mathrm{~m}^{2}$ were excavated. The AMS

radiocarbon dates from $\mathrm{Na}$ Masimasi indicate that the site was first occupied around 2700 BP (Jones 2009b; Jones and Quinn 2009). Lapita dentate potter was recovered as well as an abundance of Plainware. The site's later phase occupation is represented by Navatu style pottery. Over 12,000 vertebrate bones and 3000 invertebrates have been identified from $\mathrm{Na}$ Masimasi.

Fourth I draw from more recent research in 2013-2015 on the island of Vanua Levu at the site of Nukubalavu, which is located at the head of Natewa Bay (Jones and Cramb in prep.; Jones et al. 2014). The site is on the beach back of a small peninsula (ca. $1.3 \mathrm{~km} \mathrm{long)} \mathrm{that}$ projects out into the bay. In $14 \mathrm{~m}^{2}$ of excavations I recovered late Lapita dentate ceramics as well as an abundance of Plainware and Navatu pottery during excavations. AMS Radiocarbon dates as well as ceramic remains suggest that occupation of this site begins at approximately 2800-2100 BP in the Late Lapita period (Jones and Cramb in prep.). The vertebrate fauna from Nukubalavu is very sparse with less than 200 identified NISP. The invertebrates were relatively abundant, however, and approximately 25,000 specimens were identified.

\section{RESULTS}

Below I present archaeological results from my study sites. These data provide a wealth of information; nevertheless, faunal data are often difficult to relate directly to ethnographic questions about daily life. Recall that my goal is to use the animal remains, as other forms of material culture are more commonly used, in order to examine identity in Fiji's deep past. Food provides evidence about contexts in the past where identity was constructed, reinforced, and re-evaluated daily. Both daily food rituals and more elaborate engagements around the table involved activities and material items that reinforced identity, sociality, and community. 


\section{Bourewa}

At Bourewa the vertebrate remains from the early Lapita occupation are dominated by a suite of fauna including reef fishes, sea turtles, and megapodes. The large-bodied flightless megapodes and sea turtles are rare in Fijian archaeological sites. But their occurrence is not surprising since this material represents the first colonization of Viti Levu and fine mesh screens were not used in excavations. Marine foraging practices are clearly evidenced at Bourewa and the nearby sites by the presence of copious invertebrates, sea turtles, and a range of large and smallbodied coral reef fishes. Terrestrial animals and domestic species were also consumed. Iguanas, chickens, dogs, and pigs were recovered from the site although in much smaller frequencies (in the case of pigs they may postdate Lapita). Overall the first Lapita people to occupy Fiji at Bourewa appear to have relied on and preferred a great deal of marine reef resources. This was supplemented with wild terrestrial and domestic animals.

\section{Aiwa Levu and Aiwa Lailai, Lau Group}

The islands of Aiwa Levu and Aiwa Lailai are currently uninhabited. At Aiwa's early phase sites, I identified a high frequency of relatively small-bodied marine fishes and invertebrates in abundance. The dominant taxa include: tangs, parrotfish, wrasse, groupers, Turbo spp., limpets, and mussels. Less abundant were terrestrial animals such as lizards, boa constrictors, and bats. There is some evidence for the consumption of domestic animals in both the early and later phases occupations. The mid-sequence assemblages include much of the same taxa as the early phases but they also incorporate triggerfish, emperor fish, and chiton.

\section{Na Masimasi, Nayau}

The site of $\mathrm{Na}$ Masimasi on Nayau has a Lapita phase assemblage that is rich in very small-bodied fishes. Specifically, the mean estimated weight of the fish individuals is only 118 grams. Fishes include a high frequency of tangs, groupers, porcupine fish, and parrotfish. This focus on diminutive species is surprising. Later, during the mid-sequence and beyond, assemblages included porcupine fish, triggerfish, tangs, emperor fish, groupers, Polynesian rats, a small number of domestic animals (pigs, dogs), turbans, mussels, and cones. The mean weight of the fishes from middens in the later period is $298 \mathrm{~g}$, a significant increase in size and mass over the island's Lapita period. Clearly, the people of Nayau, including the island's first inhabitants and the contemporary villagers enjoy eating small reef fishes.

\section{Nukubalavu 1, Vanua Levu}

The early and later phase faunal assemblages from Nukubalavu (ca. 2800-600 BP) contained very few vertebrate remains (Jones and Cramb in prep.). In 14 square meters with each unit extending over $120 \mathrm{~cm}$ deep (and some up to $2 \mathrm{~m}$ ), I recovered less than 200 small bone fragments weighing a total of 50 grams. This finding was unexpected and differs markedly from the other sites; it likely relates to preservation issues. Identified vertebrates include several fragments of sea turtle carapace (some from subadult individuals, and some with evidence of burning), and a canine from a dog. However, the invertebrate assemblage was abundant and diverse across the Lapita and mid-sequence occupations. Over 25,000 shellfish were identified, including 60 taxa. A suite of seven taxa dominate the assemblage across time. This includes: periwinkles, moon turbans, nerites, sandy beach clams (Atactodea striata), Venus clams (Gafrarium tumidum), Turbo sp., and conchs. The invertebrate assemblage does not provide evidence for shifts in exploitation patterns over time. Across Lapita, Plainware, and Navatu ceramic phases the fauna remains similar and it is consistently composed of a large quantity and high diversity of essentially the same invertebrate taxa.

\section{RITUAL AND FOODWAYS}

At each of the study sites, an understanding of foodways can be combined with contextual information from features, architecture, material culture, and ethnographic data to illuminate aspects of group identity in the past. I begin this process from the perspective that identity is performative and part of a complex interplay between humans and the world around them, including material items, the environment, and food. We may come to better understand food remains as evidence for social gatherings where identity was constructed in the past, reinforced, and reevaluated on a regular basis. Rather than simply reflecting social relationships, status, and gender, meals provide a carefully structured context for the renegotiation of identity. When Fijians eat any one person's position relative to others is apparent--that is, the order in which people eat expresses they social position in the group. High ranked men eat first, then women eat, and finally children eat the leftovers. Specific foods also convey messages about status and gender during a meal. Community and a collective identity is also reinforced through the communal act of eating together and socializing. Thus, the materiality of objects, and food items in this case, make what Yvonne Marshall calls, "...the intangible manifest, that is, to make the effects of human ideas, intentions and actions visible and materially present" (2008:61).

While the search to understand identity in Fijian prehistory is currently incomplete and a work in progress, I observe some general patterns in the data presented. Importantly, I note that because foodways obviously include both animal and plant based items, a robust picture of Fijian culinary practices in the past must involve more than zooarchaeology and ideally, it includes isotope studies, and archaeobotanical analysis. Some of my previous work incorporates isotopic data and like the faunal data, suggests that the diets of Lau Islanders were different from that observed elsewhere in both the main Fiji Islands, and Remote Oceania - the Lau people rely more on inshore marine resources and tubers make up around $65-70 \%$ of what is consumed (Jones and Quinn 
2009). The collective identity of Lau Islanders clearly relates to the act of consuming large amounts of inshore marine foods including fish, shellfish, and seaweeds.

The data I have presented suggests continuity in some aspects of the local food systems from each site across time. That is, the lived experiences of the people who occupied these sites across the Fiji Islands involved the mass consumption of a wide diversity of inshore marine foods and small fishes in particular. In sum, I see three key patterns that provide an outline for future investigations; each will be addressed in more detail below:

Trends in a high diversity of marine foods as food staples across time and throughout my study samples (in suites of key taxa).

Subtle variations in key food items (especially meats) at different sites/some periods.

Lau Islanders had food systems that differ from other regions in Fiji (more small reef fish, tubers as a major staples of cuisine by 2700 cal BP).

The assemblages produced a high diversity of marine taxa and patterns suggest that a suite of key foodstuffs and/or meat items characterize foodways at various phases of prehistory (Table 1). Interestingly, some food differences correlate with changes in pottery styles (for example, the shift from early to mid-sequence occupation at $\mathrm{Na}$ Masimasi when the average size of fishes consumed increases). Conversely there is also evidence for consistency across time without major changes in the assemblages. This is the case when the assemblages are viewed broadly; there is a great deal of continuity at all the sites and an overarching emphasis on reef resources across time and space. Direct continuity can also be found in some of the specific assemblages, for example on Nukubalavu the zooarchaeological data does not express evidence of shifts over a long time frame and across Late Lapita, Plainware, and Navatu phases of the excavations that span several thousand years. Just as Chenoweth noted in his archaeological study of identity, '...change associated with ephemeral social identities can still point to stable social reality' (Chenoweth 2009:320). That reality for Fijians was one that associates marine foods, reef resources, and tubers with expressions of and reflections on group identity.

Undoubtedly some variations in foodways are related to subtle differences in local ecologies. For example, Lau Islanders had food systems that differ from the larger islands of West Fiji, as they consumed more small fishes and tubers as major staples of cuisine even as early as $2700 \mathrm{cal}$ BP. Environmental variations cannot explain the whole story, as exemplified from the assemblage at $\mathrm{Na}$ Masimasi that provided evidence of a shift from small reef fishes to slightly larger reef fishes over time and it produced little evidence for domestic animals. This finding is surprising based on comparative studies and basic assumptions about marine exploitation over time and the presumed environmental impacts of these practices. Despite the great diversity of fishes in the waters around Fiji, the people of the Lau Islands enjoyed eating very small-bodied fishes from the time of the earliest occupation of the island group.

Substantial differences in the assemblages are found in the local, often subtle site-specific variations in foodrelated practices. In particular, there are differences in the consumption of meats items at each site. I propose that this is where our attention might be most productively focused in order to examine Fijian concepts of identity and ethnicity. Staple elements of a cuisine and group preferences for certain dishes or ingredients are part of elaborate ethnic-, village-level, or even householdspecific systems that may or may not shift in perceptible ways with obvious faunal correlates. Therefore, a large sample and multiple lines of evidence are required to fully explore the relationship between eating, identity, and ethnicity.

Ethnographic data describes the critical role that feasts and large displays of food play in Fijian culture. The widespread occurrence of such ideas in Fiji and elsewhere in the Central Pacific islands suggests that all important ceremonies included feasts in both the past and the present (Jones 2009a, 2009b). Food for most feasts differs from that of the daily meal in terms of a much larger quantity of food, a wider diversity of food, and the addition of a sweet baked pudding made from mashed root crops and a caramelized coconut milk. Turtle and pig are described in many ethnographic accounts as great delicacies served only at important events for high ranking persons. Turtle, pig, and certain large bodied fishes are considered as the most prestigious foods, that is items that are suitable for sacrifices and tribute to people of rank. Perhaps the food remains from Bourewa represent such feast foods and specialty items. Remains of domestic animals and sea turtles are rare across the analyzed assemblages. In terms of identity, it is possible that the people who occupied Bourewa were high ranking as indicated by their foods.

Mary Douglas (1975) argued that the meaning of a meal is found in the system of repeated analogies where each meal is a structured social event--this provides the framework for organizing other events according to the same pattern. Douglas explained that meals, like all cultural phenomena are structured through practice, a process that creates and maintains meaning. In this way, every meal in Fiji is structured, following hierarchical principles and traditional cultural norms. Despite colonialism and Christianization of the Fijian Islands, “...production, exchange, tribute, and consumption...are still distinctly Fijian...[and]...eating together still defines the household..." (Toren 1998:113). Every meal is structured as a feast at a smaller less formal scale. Hocart noted that a "small private feast is often called an oven (lovo)" (Hocart 1929:75). In a contemporary setting an earth oven (lovo) is used about once a week to prepare food, but often more regularly depending on the household and the occasion. Normal patterns of food consumption and what constitutes a 'meal' at a basic level may be viewed as a small-scale feast (but, with less quantity overall, no pudding, and lacking an abundance of 
meat from domestic animals - chicken, pig, dog, cow) (Becker 1995:58; Jones 2009a). Large piles, and mass quantities of a diversity of foods express power, prestige, and community; at the same time when people eat together identity is negotiated and group members performatively make culture. The Fijian meal is dependent on presentation as well as the presence of the proper constituents (starches and meats). A good meal is always shared and it always involves an abundant spread that challenges the diners' abilities to consume everything. As such, food remains, the copious vertebrate and invertebrate fauna identified from archaeological sites, are the residues of events that reinforced and made social identity. Fijian identity is forged via culinary practice, exchange, and the creation of social meaning. This process is inherently an act of self-expression, while at that same time it is derived from a specific historical trajectory that involves social and material relationships.

\section{ACKNOWLEDGMENTS}

I thank Dr. Patrick Nunn for providing me with the fauna from Bourewa, One Hundred Sands Ltd. and Barbara L'Ami for allowing me to work on Nukubalavu, and the people of Lakeba and Nayau for permitting and facilitating my work in the central Lau Group. I am grateful to the Fiji Museum, and especially Ratu Jone Balenaivalu and Sepeti Matararaba, for making this work possible and successful. Joe Kevu, Sepesa Colati, and Rusila Colati, provided critical assistance in the field. The material and data presented in this report is based upon work supported by the National Science Foundation (NSF) under Grant \#13599547 to the author as well as funding from the National Geographic Society. Any opinions, findings, and conclusions or recommendations expressed in this material are those of the author and do not necessarily reflect the views of the funding agencies.

\section{REFERENCES}

Becker, Anne E. 1995. Body, Self, and Society: A View from Fiji. Philadelphia: University of Pennsylvania Press.

Best, Simon B. 1984. Lakeba: The Prehistory of a Fijian Island. Ph.D. Thesis, University of Auckland. Ann Arbor, Michigan: University Microfilms.

Burley, D. V. 2005. Mid-Sequence archaeology at the Sigatoka Sand Dunes with interpretive implications for Fijian and Oceanic culture history. Asian Perspectives 44 (2): 320348.

Burley, David V. 2012. Exploration as a strategic process in the Lapita Settlement of Fiji: The implications of Vorovoro Islands. Journal of Pacific Archaeology 3(1):1-13.

Burley, David. V. 2013. Fijian Polygenesis and the Melanesian/Polynesian Divide. Current Anthropology 54(4): 436-462.

Casella, E. and Fowler, C. (eds.). 2005. The archaeology of plural and changing identities: beyond identification. London: Springer Science \& Business Media.

Chenoweth, John M. 2009. Social identity, material culture, and the archaeology of religion: Quaker practices in context. Journal of Social Archaeology 9(3):319-340.
Clark, Geoffrey R. 1999. Post-Lapita Fiji: Cultural Transformation in the Mid-sequence. Unpublished $\mathrm{PhD}$ thesis, Department of Archaeology and Natural History Research School of Pacific and Asian Studies, Australian National University, Canberra.

Clark, Geoffrey R. 2009. Post Lapita ceramic change in Fiji. In G. Clark and A. Anderson (eds.), The Early Prehistory of Fiji. Terra Australis 31, pp. 307-320. Canberra: Australian National University.

Counihan, Carole. 2004. Around the Tuscan Table: Food, Family, and Gender in Twentieth-Century Florence. New York: Routledge.

Douglas, Mary. 1975. Deciphering a meal. In M. Douglas (ed.), Implicit Meanings: Essays in Anthropology, pp. 249-275. London: Routledge \& Kegan Paul.

Franklin, M., and G. Fesler (eds.). 1999. Historical Archaeology, Identity Formation, and the Interpretation of Ethnicity. Williamsburg: Colonial Williamsburg Foundation.

Gilchrist, R. 2012. Gender and Archaeology: Contesting the Past. London: Routledge

Hocart, A. M. 1929. Lau Islands, Fiji. B. P. Bishop Museum Bulletin 62. Honolulu: Bishop Museum Press.

Hodder, Ian, and Craig Cessford. 2004. Daily Practice and Social Memory at Çatalhöyük. American Antiquity 69:1740.

Hodder, I. and Meskell, L. 2011. A "Curious and Sometimes a Trifle Macabre Artistry" Some Aspects of Symbolism in Neolithic Turkey. Current Anthropology 52(2):235-263.

Insoll, Timothy (ed.). 2007. The Archaeology of Identities: A Reader. London: Routledge.

Jones, S., D. W. Steadman, and P. O’Day. 2007. Archaeological investigations on the small islands of Aiwa Levu and Aiwa Lailai, Lau Group, Fiji. The Journal of Island and Coastal Archaeology 2(1):72-98.

Jones, S. 2009a. Food and Gender in Fiji: Ethnoarchaeological Explorations. Lanham and New York: Lexington Books/ Rowman \& Littlefield.

Jones, S. 2009b. A long-term perspective on biodiversity and marine resource exploitation in Fiji's Lau Group. Pacific Science 63(4):617-648.

Jones, S. and J. Cramb. 2016 (in prep.). Dating a Small Island Settlement in Fiji: Bayesian Modelling of the Nukubalalvu Site on Vanua Levu. Paper submitted to a special issue of the Journal of Island and Coastal Archaeology (expected publication 2017).

Jones, S. and R. L. Quinn. 2009. Prehistoric Fijian Diet and Subsistence: Integration of Faunal, Ethnographic, and Stable Isotopic Evidence from The Lau Island Group. Journal of Archaeological Science 36:2742-2754. http://dx.doi.org/10.1016/j.jas.2009.08.014

Jones, S., Carlisle, C., Schafer, J. Ryder, C.Y., Mullins, S., Reed, K., Ledford, K., Pearson, P., Rouse, A., Bridgeman, L. and C. Callahan. 2014. Report submitted to the Fiji Museum and on file with Domodomo.

Lazzari, Marisa. 2005. The texture of things: objects, people, and landscape in Northwest Argentina (First Millennium A.D.). In, L. Meskell (ed.), Archaeologies of Materiality, pp. 126-161. Oxford, UK: Blackwell Publishing. 
Marshall, Yvonne. 2008. The social lives of lived and inscribed objects: A Lapita perspective. Journal of the Polynesian Society 117(1):59-101.

Meskell, Lynn. 2002. The intersections of identity and politics in archaeology. Annual Review of Anthropology 31:279301.

Meskell, Lynn (ed.). 2005. Archaeologies of Materiality. Blackwell: Oxford.

Nunn, P.D., Kumar, R., Matararaba, S., Ishimura, T., Seeto, J., Rayawa, S., Kuruyawa, S., Nasila, A., Oloni, B., Ram, A.R., Saunivalu, P., Singh, P., and E. Tegu. 2004. Early Lapita settlement site at Bourewa, Southwest Viti Levu Island, Fiji. Archaeology in Oceania 39(3):139-143.

Nunn, P. D. and F. Petchey. 2013. Bayesian re-evaluation of Lapita settlement in Fiji: radiocarbon analysis of the Lapita occupation at Bourewa and nearby sites on the Rove Peninsula, Viti Levu Island. Journal of Pacific Archaeology 4(2)21-34.

O'Day, S. Jones 2004.Past and present perspectives on secular ritual: food and the fisherwomen of the Lau Islands, Fiji. In S. J. O'Day, W. Van Neer, and A. Ervynck (eds.), Behaviour Behind Bones: The Zooarchaeology of Ritual, Religion, Status, and Identity, pp.153-161. Oxford, UK: Oxbow Books.

O'Day, S. J., O'Day, P., and Steadman, D. W. 2003. Defining the Lau Context: Recent Findings on Nayau, Lau Islands, Fiji. New Zealand Journal of Archaeology 25:31-56.

Pierce, E., Russell, A., Maldonado, A., and L. Campbell (eds.). 2016. Creating Material Worlds: The Uses of Identity in Archaeology. Oxford: Oxbow Books.

Pollan, M. 2013. Cooked: A Natural History of Transformation. New York: Penguin Press.

Sahlins, Marshall D. 1983. Raw women, cooked men, and other "great things" of the Fiji Islands. In P. Brown and D.
Tuzin (eds.), The Ethnography of Cannibalism, pp. 72-93. Washington D.C.: A Special Publication of the Society for Psychological Anthropology.

Tomlinson, M. 2014. Ritual Textuality: Pattern and Motion in Performance. Oxford: Oxford University Press.

Toren, C. 1990. Making Sense of Hierarchy: Cognition as Social Process in Fiji. LSE Monographs in Social Anthropology, 61. London: Athlone Press.

Toren, C. 1998. Cannibalism and compassion: transformations in Fijian concepts of the person. In V. Keck (ed.), Common Worlds and Single Lives: Constituting Knowledge in Pacific Societies, pp.95-115. Oxford, UK: Berg.

Toren, C. 2009. Intersubjectivity as epistemology. Social Analysis 53(2):130-146.

Twiss, Katheryn C. (ed.). 2007. The Archaeology of Food and Identity. Issue 34 of Occasional Papers of the Center for Archaeological Investigations, Southern Illinois University Carbondale.

Twiss, K. 2012. The Archaeology of Food and Social Diversity. Journal of Archaeological Research 20(4):357-395.

Twiss, K. 2015. Food and Identity. In, M. Beaudry and K. Metheny (eds.), The Archaeology of Food: An Encyclopedia, pp. 189-191. Walnut Creek, CA: Alta Mira Press.

White, C.L. and M.C. Beaudry. 2009. Artifacts and personal identity. In T. Majewski and D. Gaimster (eds.), International Handbook of Historical Archaeology, pp. 209-225. New York: Springer.

Wilson, Gregory D. 2010. Community, identity, and social memory at Moundville. American Antiquity 75(1):3-19.

Wrangham, Richard. 2009. Catching Fire: How Cooking Made Us Human. New York: Basic Books. 